\title{
Route Generation Heuristics for the Automated Creation of Hot Spot Policing Patrol Routes
}

\section{A PREPRint}

\author{
Francisco Carlos F. Nunes Junior \\ Insight Data Science Lab \\ Federal University of Ceará \\ Fortaleza, 60440-900, Brasil \\ carlos@insightlab.ufc.br \\ Spencer P. Chainey \\ Department of Security and Crime Science \\ University College London \\ London, WC1H 9EZ, England \\ spencer.chainey@ucl.ac.uk
}

\author{
Jhonata A. S. Matias \\ Insight Data Science Lab \\ Federal University of Ceará \\ Fortaleza, 60440-900, Brasil \\ jhonatadam@gmail.com
}

\author{
Ticiana L. Coelho da Silva \\ Insight Data Science Lab \\ Federal University of Ceará \\ Fortaleza, 60440-900, Brasil \\ ticianalc@insightlab.ufc.br
}

\author{
José Antônio F. de Macêdo \\ Insight Data Science Lab \\ Federal University of Ceará \\ Fortaleza, 60440-900, Brasil \\ jose.macedo@insightlab.ufc.br
}

\author{
Regis P. Magalhães \\ Insight Data Science Lab \\ Federal University of Ceará \\ Fortaleza, 60440-900, Brasil \\ regis@insightlab.ufc.br
}

\author{
José F. de Queiroz Neto \\ Insight Data Science Lab \\ Federal University of Ceará \\ Fortaleza, 60440-900, Brasil \\ florencio@insightlab.ufc.br
}

\author{
Wellington Clay Porcino \\ Insight Data Science Lab \\ Federal University of Ceará \\ Fortaleza, 60440-900, Brasil \\ wellington. wcps@gmail .com
}

August 13, 2021

\begin{abstract}
Hot spot policing is a form of targeted police patrol deployment for decreasing crime. For hot spot policing to be effective, it requires analysis of crime data to identify the specific locations where crime is concentrated and create suitable patrol routes. The creation of hot spot policing patrol routes is a manual task that police officers perform, requiring skills and knowledge about hot spot policing and crime pattern analysis. This can limit the use of hot spot policing where these skills and knowledge are not available, and where they are available, the creation of patrol routes can be a time-consuming task. In this paper, we introduce two computational route generation heuristics that automate creating hot spot policing patrol routes. Both approaches identify the specific locations where crime concentrates and then use different methods to create the patrol routes. We compare the performance of each approach using metrics associated with effective patrol route creation and through visual inspection. We conclude that the heuristics we introduce provide an accurate means for creating hot spot policing patrol routes, which can support greater and improved use of hot spot policing as an effective type of intervention for decreasing crime.
\end{abstract}

Keywords hot spots $\cdot$ patrol routes $\cdot$ crime data $\cdot$ street network $\cdot$ street segments $\cdot$ graph algorithms 


\section{Introduction}

Police patrol is one of the most important activities the police perform. Ever since police agencies were first established over 150 years ago, patrolling the streets has been a core police function. The physical presence of police officers patrolling the streets aims to prevent crimes by deterring offending behaviour and can allow police officers to quickly respond to criminal incidents that take place nearby [Ratcliffe and Sorg. 2017]. The police patrol function consumes a large number of police resources. However, much of the time spent while on patrol is unsupervised, with the decision of where to patrol often at the discretion of the patrol officer [Gaines et al., 2007]. Studies that have examined police patrol deployment that is unsupervised and not directed to areas in need have found that police patrol has a limited impact on decreasing crime [Kelling et al., 1974] [Sherman et al., 1989]. Identifying crime hot spots and targeting the deployment of police patrols to these hot spots is a proven way to improve the effectiveness of police patrols [Braga et al. 2019a]. Crime hot spots are areas where crime is observed to highly concentrate, with this patterning observation being consistent in a wide range of urban settings [Chainey et al., 2019] [Lee et al., 2017] [Sherman et al., 1989] [Weisburd, 2015].

When implementing a hot spot policing intervention, a police agency's critical challenge is determining where the police patrols should be deployed accurately and the patrol route to take. Deciding where to deploy hot spot policing patrols can be a time-consuming task, involving two key factors. First, the patrols need to be targeted to specific locations where high levels of crime concentrate. This involves an analysis of crime patterns to determine where these areas of high crime concentration are located. In hot spot policing, the street segment (the section of a street between two junctions) is the geographic unit of analysis most used to determine the areas of high crime concentration. The analysis of crime concentration for hot spot policing, therefore, involves identifying the street segments that account for the highest concentrations of crime [Chainey, in press 2021] - we refer to these street segments as hot segments. Second, the patrol route should include these hot segments but may also need to include traversing along other streets that are no hot spots to reach other hot segments. This is because it is impractical, in police personnel terms, to deploy a police patrol to a single hot segment in a city when other hot segments also require the attention of police patrols. Therefore, hot spot patrol routes need to include patrolling a group of interconnected street segments, which ideally consist of several hot segments. When the streets to patrol have been identified based on most needs (i.e., they are the streets with the highest levels of crime), this allows police patrol supervisors to issue clear instructions on where police officers should patrol. Also, this can help to overcome patrol officers self-initiating patrols in areas of less need (to occupy their time) [Famega et al. 2005] and instead of using their time more effectively by patrolling areas where their presence is more likely to prevent crime. Therefore, a key component in deciding where to deploy hot spot policing patrols is to analyse spatial patterns of crime to identify the hot segments where police patrols should be deployed, and from this design patrol routes that effectively cover these hot segments.

In this paper, we introduce and compare two algorithms that generate the routes for hot spot policing patrols. The algorithms we introduce had two research aims: (1) to identify the streets of highest crime concentration (i.e., the hot segments), and; (2) to create patrol routes consisting of multiple street segments that cover areas with the highest levels of crime and that are of a reasonable length for hot spot policing patrol deployment. We measure the algorithms' performance using several metrics associated with effective patrol route creation and visual inspection.

The remainder of this paper is organized as follows: In Section 2, we discuss the challenges in designing effective hot spot policing patrol routes. In Section 3, two proposed heuristics are described and discussed for creating hot spot policing patrol routes. In Section 4, we describe how each method was evaluated and present the results. In Section 5, we discuss the findings, propose future research, describe limitations of the current study, and provide conclusions.

\section{Preliminaries and Related Works}

\subsection{Crime Concentration and Hot Spot Policing}

Hot spot policing involves deploying police personnel to specific locations where crime is known to concentrate highly. Hot spot policing aims to reduce crime by countering the geographically concentrated nature of crime [Braga and Weisburd, 2010] [Sherman and Weisburd, 1995a] and focusing the deployment of police patrols more efficiently and proactively. Focusing police attention on the places where a large proportion of crime is committed is considered to have an overall impact in decreasing crime. Evaluations of hot spot policing programs have shown they can lead to significant decreases in robbery [Sherman and Weisburd, 1995b] [Chainey et al., 2020], violent crime [Ratcliffe et al., 2011], burglary [Weisburd and Green. 1995] [Andresen and Lau. 2014], and drug offences [Lawton et al., 2005], with evidence also showing that crime does not significantly displace from the targeted patrol areas to other areas [Braga et al. 2019b]. Hot spot policing can also improve the public's perception of security [Collazos et al. 2020].

Hot spot policing aims to counter the consistently observed pattern that a small number of places in a city account for a large proportion of crime [Chainey et al. 2015] [Lee et al., 2017] [Sherman et al., 1989] [Weisburd, 2015]. For 
example, in New York City, Vancouver, Medellín, and Rio de Janeiro, studies have shown that less than five percent of places accounted for 50 percent of all crimes [Weisburd et al., 2014] [Chainey and Monteiro, 2019] [Curman et al. 2015] [Ortega et al. 2015]. Street segments are the unit of study for most examinations of spatial crime concentration because they are behavioural activity settings that precisely capture the situational opportunity structure of crime events and local social conditions [Weisburd, 2015]. To determine where hot spot policing patrols need to be deployed requires an analysis that identifies the specific street segments that account for the highest crime levels. This involves analyzing the distribution of crime across all street segments in a study area to determine those street segments that account for a cumulative total of 25 percent and 50 percent of crime [Chainey, in press 2021] (i.e., the most criminogenic areas of a city). This analysis results in the identification of hot street segments that then form the basis for determining where hot spot police patrols should be deployed.

Often, only six percent of a patrol officer's time is assigned to activities that have been directed by supervising officers, is in response to calls for service directed by emergency number dispatchers, as back up to requests from other officers, or directly in response to citizen requests [Famega et al., 2005]. This means that patrol officers have much unassigned time, which is often used at their discretion to self-initiate routine patrol. Where the patrol officer decides to patrol is often not guided by crime analysis [Chainey et al. 2020]. Identifying the areas where patrol officers should be deployed so that their time is spent proactively preventing crime is vital to better utilizing the police patrol function. Two types of approaches are most used to pratice how police patrols are deployed to crime hot spots. One approach involves creating a specific intervention that allocates patrol officers to perform the specific task of patrolling hot spots during an operational assignment. For example, during a four-hour assignment, police officers patrol a hot spot route(s) during the assignment (see [Chainey et al., 2020] for an example of this approach). The second approach involves patrol officers spending time unassigned to activities during their operational shift to patrol hot spots. For example, during an eight-hour operational shift, when a police patrol is not responding to calls for service, the police officers patrol the hot spots that have been assigned to them (see [Collazos et al., 2020] for an example of this approach). Both approaches rely on identifying hot spots and the routes to take within these hot spots.

Hot spot policing primarily works by aiming to deter a person from committing a crime. The visible presence of a police patrol in a crime hot spot makes the offender think that it is now riskier for them to commit a crime in an area where they previously committed many crimes. Koper [Koper, 1995] has previously determined that the optimal time duration that police should spend in a crime hot spot is 15 minutes per hour. That is, patrol a hot spot for 15 minutes and then return an hour later for a further 15 minutes. For crimes such as robberies and thefts against pedestrians, foot patrol is the best type of hot spot policing patrol, whereas for crimes that involve both the offender and victim using vehicles (e.g., the robbery of car drivers by offenders on motorbikes), vehicle patrol is considered to be the best type of patrol [Chainey et al. in press 2021]. The average pace a person walks is about 5 to $7 \mathrm{~km}$ per hour. As police patrols are often required to stop and observe behavior, and stop and talk to citizens while on patrol, in 15 minutes, a foot patrol can be expected to cover a hot spot patrol route of approximately $1 \mathrm{~km}$ in length. Although vehicle patrols may be able to cover longer hot spot patrol routes, most research indicates that foot patrols in crime hot spots rather than vehicle patrols have a more significant impact on crime [Ratcliffe and Sorg. 2017].

\subsection{Problem Statement}

In this paper, we describe two algorithms for creating hot spot policing patrol routes on street networks. Our focus is on creating foot patrol routes. The algorithms aim to create optimal hot spot policing patrol routes, measured in terms of the level of crime previously committed on the streets where the patrol routes are created while also being constrained by the practical distance a police foot patrol can walk. The two algorithms involve two separate approaches to achieving the same aim. Both algorithms use the same results from an analysis of the distribution of crime that had identified hot street segments - these being the most criminogenic street segments accounted for $\mathbf{5 0 \%}$ of all crime. The crime type of interest in the current study is robbery from a pedestrian. When designing a hot spot policing program, the analysis of geographic crime concentration should involve analysis of specific types of crime rather than all types of crime [Chainey, in press 2021]. Many hot spot policing programs aim to decrease robberies from pedestrians [Braga et al., 2019a], and hence it was the crime type that was chosen for analysis in the current study. The analysis to identify the most criminogenic street segments that accounted for $\mathbf{5 0 \%}$ of all crime followed the procedure described by [Chainey, in press 2021]. This involved using robbery data that had been geographically referenced to street segments to calculate the number of robberies on each street segment, from which the lowest number of street segments accounted for $\mathbf{5 0 \%}$ of all robberies were identified. We provide further details about the data we use and the analysis of crime hot spots in the Experimental Setup section, where we also report on geographic crime concentration levels for each of our study areas.

A condition placed on each algorithm was that the start and end location of the patrol route must be the same because this is what is often most done in practice when patrolling a crime hot spot. This means that a route could be a simple circular path around street segments or could consist of a more complex arrangement of paths for a patrol route, albeit still starting and ending at the same point. Before formally describing the problem, we describe preliminary notations and terms. 
Definition 1. A Street Network $G=(V, E, l, w)$ is a weighted and undirected graph, with $V$ as the set of vertices (i.e., street junctions), $E$ the set of edges (i.e., street segments), $l: E \mapsto \mathbb{R}^{+}$a length function and $w: E \mapsto \mathbb{R}^{+}$a weight function.

An edge $e=\left(v_{s}, v_{t}\right) \in E, l(e)$ is the spatial distance between $v_{s}$ and $v_{t}$, both vertices in $V$. There are several possibilities for the weight function $w$. Before discussing these, consider $C r=\left\{c r_{1}, c r_{2}, \ldots, c r_{m}\right\}$ as the set of crime locations, such that each crime incident $c r_{i} \in C r$ is map-matched to the nearest edge $e \in E$.

Definition 2. Let the weight function $w(e)$ be the number of crime incidents mapped to $e \in E$. Let $H$ represent the top- $n$ edges with the highest crime concentration, i.e., together all the edges in $H$ should concentrate more than $\alpha \%$ of crime incidents. An edge $e \in E$ is a hot segment if and only if $e \in H$.

Now, we can formalize a route in the street network $G$.

Definition 3. A Route $r$ of a graph $G=(V, E, l, w)$ is a sequence of vertices $r=\left(r_{1}, r_{2}, \ldots, r_{n}\right)$ with $r_{1}=r_{n}$ and $\left(r_{i-1}, r_{i}\right) \in E, \forall i \in\{2,3, \ldots, n\}$. We denote the set of edges in $r$ by $\sigma(r)=\left\{\left(r_{i-1}, r_{i}\right): i \in\{2,3, \ldots, n\}\right\}$ and the length and weight of $r$ by $L(r)=\sum_{i=2}^{n} l\left(r_{i-1}, r_{i}\right)$ and $W(r)=\sum_{\left(r_{i-1}, r_{i}\right) \in \sigma(r)} w\left(r_{i-1}, r_{i}\right)$, respectively.

Definition 4. Let $H$ be the hot segments in $G$. The route $r$ is a Patrol Route if there exists at least one edge $\left(r_{i-1}, r_{i}\right) \in \sigma(r)$, such that $\left(r_{i-1}, r_{i}\right) \in H$.

As mentioned previously, a patrol route can consist of a single circular path around a network of streets or may involve a more complex path (e.g., consisting of multiple circular paths around the street network within a single patrol route). In all cases, the start and endpoint of the patrol route is the same location. We define a cycle $c$ of a route $r$ to be a subsequence of consecutive edges that can be extracted from $r$ in which no vertex except the first (which is also the last) appears more than once.

Next, more formally, we define our problem of finding the hot spot policing patrol route as follows.

Problem Definition. Let $G=(V, E, l, w)$ be the street network, $C r$ the set of past crime incidents, $H$ the set of hot segments in $G, m$ the minimum length of a route, $M$ the maximum length of a route and $k$ the maximum number of routes. Let $S \subseteq R(G)=\{r$ : is a route of $\mathrm{G}$, such that $m \leq L(r) \leq M\}$. Hence, the problem to be solved is to find a set $S$ of $k$ routes $r$ that take the past crime incidents $C r$ and the hot segments $H$ into account, and where each route is of a practical length. We also aim to find the routes in the shortest time, so the approach is flexible to any ad hoc policy demands.

Of course, the problem is generic, and $S$ can be any set of $k$ patrol routes that respect the maximum and minimum route length restrictions in $G$. To measure the quality of each patrol route $r \in S$ that is created using our approach, we introduce four metrics $H L F(r), N R E F(r), C D I(r)$ and $W(r)$. The first is related to the proportion of a patrol route (in terms of length) that are hot segments. The second metric measures how much of the route consists of edges that are not repeated. In practice, and to ensure optimal patrol coverage, police patrols aim to avoid traversing the same street twice as this duplicates their presence on this street at the potential cost of not patrolling another street where their presence is required [Ratcliffe and Sorg, 2017] [Chainey et al., in press 2021]. The third metric measures the density of crime incidents for the street segments in $r$. The fourth metric is the number of crimes that were previously committed on the route.

Definition 5. The Hot segments Length Factor (HLF) for a route $r$ in the street network $G=(V, E, l, w)$ is the ratio between the sum of the length of hot segments in $r$ and the length of $r$.

$$
H L F(r)=\frac{\sum_{i=2:\left(r_{i-1}, r_{i}\right) \in H}^{n} l\left(r_{i-1}, r_{i}\right)}{L(r)}
$$

Definition 6. The Non-Repeated Edges Factor (NREF) for a route $r$ in the street network $G=(V, E, l, w)$ is the ratio between the sum of the length of non repeated edges in $r$ and the length of $r$.

$$
N R E F(r)=\frac{\sum_{i=2:\left(r_{i-1}, r_{i}\right) \in \sigma(r)}^{n} l\left(r_{i-1}, r_{i}\right)}{L(r)}
$$

Definition 7. The Crime Density Index (CDI) for a route $r$ in the road network $G=(V, E, l, w)$ compares the number of crimes located on $r$ and the length of $r$ with the total number of crimes and the total length considering all edges from $G$. The CDI is defined according to the following equation: 


$$
C D I(r)=\frac{W(r)}{L(r)} * \frac{\left.\sum_{\left(r_{i-1}, r_{i}\right) \in E} l\left(r_{i-1}, r_{i}\right)\right)}{\sum_{\left(r_{i-1}, r_{i}\right) \in E} w\left(\left(r_{i-1}, r_{i}\right)\right)}
$$

The metric $C D I(r)$ measures how many times the street segments in $r$ accounted for more crime than all the street segments in the street network $G$. It indicates how many times the route is "hotter" than the street network in the study area as a whole.

The fourth metric is the number of crimes that previously were committed on route $r$ and can be simply defined as $W(r)$.

\subsection{Related Works}

To date, very little research has been devoted to developing data-driven and analytically-informed decision support solutions for creating hot spot policing patrol routes [Dewinter et al., 2020]. Although the problem is associated with the dynamic vehicle routing problem (DVRP) [Pillac et al. [2013], there are peculiarities that relate to the creation of hot spot policing patrol routes that require specific consideration. This includes creating patrol routes that are only required in crime hot spots, where the length of routes seek to optimise the deterrence effect of police patrols while maximising the area a patrol can practically cover, and where the paths within a route cover street segments where the levels of crime are highest rather than the path between two points being the shortest path [Dewinter et al., 2020].

Most solutions that have been designed to support the police patrol function have focused on how to dispatch and allocate police patrols to areas rather than determining the routes the patrols should take. For example, a solution proposed by Camacho-Collados and Liberatore [Camacho-Collados and Liberatore, 2015] used a cost function (based on the topology, size, and shape of police districts, and the level of crime in each district) to determine the workload that was associated with patrolling each police district. Although this solution offered a way to allocate police patrols to districts, it did not offer a solution for creating patrol routes that cover the streets where crime hot spots were present. Similarly, Chelst [Chelst, 1978] proposed an algorithm to allocate police patrols to areas, albeit in this case crime hot spots. This algorithm was used to deploy officers one by one in an iterative process by ranking hot spots in terms of the likelihood of the patrol being able to intercept the commission of a crime. Chelst [Chelst. 1978] calculated the marginal probability of a crime incident occurring using Koopman's search theory [Koopman. 1957]. This approach offered a useful solution for real-time resource deployment but did not recognize that hot spots of crime tend to persist in certain places, and from this, police patrol routes should be created that aim to counter the concentration of crime in these places.

A solution proposed by Kuo et al. [Kuo et al. 2013] offered a simple procedure to create patrol routes. First, using incidents of crime and car crashes, they identified hot spots using Kernel Density Estimation. Then, using Dijkstra's algorithm to find the shortest paths, patrol routes were calculated that connected hot spots. In designing this approach, their goal was to reduce police dispatch time rather than reduce crime, with the patrol routes created being those that connected crime hot spots rather than creating patrol routes in the crime hot spots. A technique defined by Chen et al. [Chen et al. 2017] to create police patrol routes involved collaborative agents following a Bayesian approach in conjunction with ant-colony algorithms. The technique aimed to assist the real-time deployment of police patrols to areas by issuing instructions about where the next patrol should take place. In doing so, the time when hot spots were without any police patrol would be minimized, and the hot spots that experienced the most crime would receive the most patrol visits. Like other solutions, this solution did not create the routes within the crime hot spots, and instead focused on how patrols were dispatched to crime hot spots.

Chawathe [Chawathe, 2007], however, has proposed a solution for creating patrol routes in crime hot spots. This approach involved modelling the street network as an edge-weighted graph (weighted by the incidence of crime) and using this to consider the importance (in crime terms) of each edge (i.e., each street segment). The patrol routing algorithm that was proposed involved traversing the street network looking for the densest and largest path with the minimum number of street segments. Density was measured as the ratio between the total weight of the proposed route and the number of edges within the route. The algorithm then generated paths (patrol routes) that required the police to traverse each edge in both directions.

Table 1 shows a comparison between the techniques presented in this related research section. We compare this research by using several key characteristics associated with hot spot police patrols. In the first column, we define whether the technique described in the research identifies crime hot spots. The second and third columns refer to whether the technique relates to reactive or proactive policing (hot spot policing is the latter). The fourth and fifth columns refer to the spatial unit of the patrol (i.e., if it relates to the allocation of patrols to an area or defines street paths that the patrols should follow). In the last two columns, if the geographic unit for the patrol is the street level), the patrol routes created are compared in terms of whether they follow a linear or circular orientation. In comparing our proposed approach to 


\begin{tabular}{|c|c|c|c|c|c|c|c|}
\hline Paper & Hot spot & Reactive & Proactive & Area & Route & Linear & Circular \\
\hline Chelst $\mid \overline{\text { Chelst, }} \overline{1978}$ & - & - & $\mathrm{X}$ & $\mathrm{X}$ & - & - & - \\
\hline Chawathe [Chawathe, 2007] & - & - & $\mathrm{X}$ & - & $\mathrm{X}$ & $\mathrm{X}$ & - \\
\hline Camacho-Collados et al. Camacho-Collados and Liberatore, 2015 & $\mathrm{X}$ & - & $\mathrm{X}$ & $\mathrm{X}$ & - & - & - \\
\hline Kuo et al. Kuo et al., 2013 & $\mathrm{X}$ & $\mathrm{X}$ & - & - & $\mathrm{X}$ & $\mathrm{X}$ & - \\
\hline Chen et al. Chen et al., 2017 & - & - & $\mathrm{X}$ & - & $\mathrm{X}$ & $\mathrm{X}$ & - \\
\hline Our Approach & $\mathrm{X}$ & - & $\mathrm{X}$ & - & $\mathrm{X}$ & - & $\mathrm{X}$ \\
\hline
\end{tabular}

Table 1: Related Works Comparison.

the other solutions, our approach offers a comprehensive solution to the problem of creating hot spot policing patrol routes because it determines where the hot spots are located, it designs patrol routes that are specific to these hot spots, is in support of the ethos of hot spot policing being a form of proactive (crime prevention) policing, and optimises the patrol coverage by being circular in its orientation and by minimising the traversing of the same street segment more than once.

\section{Route Generation Heuristics}

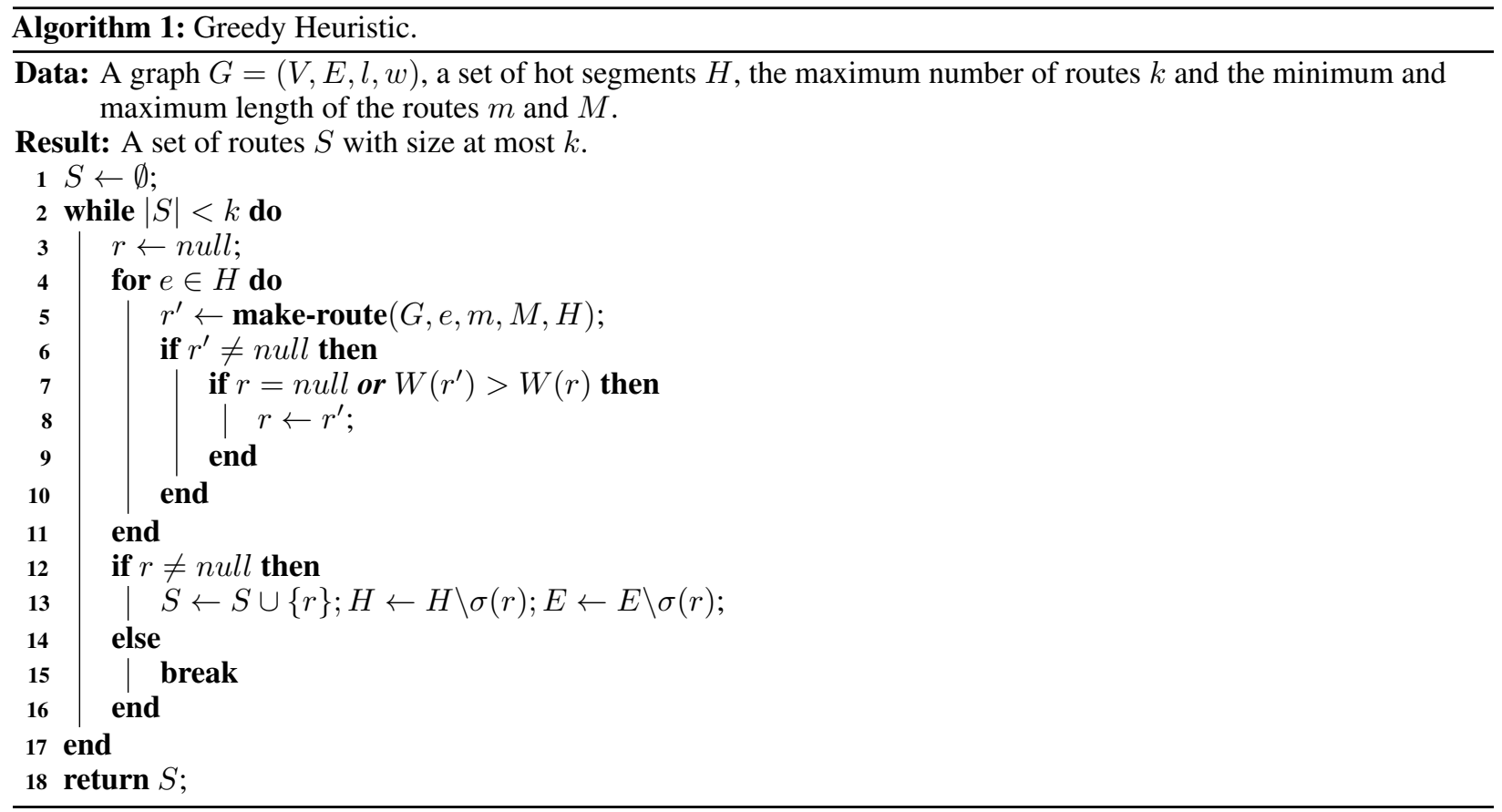

This section describes the two heuristic algorithms (named HotStar and HotSee) that are used for creating hot spot policing patrol routes. Both solutions search for the best $k$ routes, i.e., with the highest number of crimes, created from a hot segment in $H$, and respecting the minimum and maximum length, $m$ and $M$, for a patrol route. We begin by describing a Greedy Heuristic Algorithm (Algorithm 1) on which both HotStar and HotSee are based. The set of patrol routes $S$ is at first initialized as an empty set (Line 1), and stops when it finds $k$ routes in $S$ (Line 2). For each hot segment $e \in H$ (Line 4), the make-route procedure (Line 5) outputs a route $r^{\prime}$ that passes through $e$ in $G$, and with a length between $m$ and $M$. Notice that a route $r^{\prime}$ will only be included in $S$ if $r^{\prime}$ is the best route (with the maximum number of crimes) among the routes generated from the hot segments that belong to $\mathrm{H}$ (Lines 7 and 8 ). Whenever a route $r$ is included in $S$, the edges in $r$ that are hot segments are removed from $H$ and the set of edges $E \in G$ (Line 13). This means that the edges for new routes that are to be found in the next iteration of Algorithm 1 are not the same as the ones in the previous set of routes. Algorithm 1 attempts to create a new patrol route for each hot segment $e \in H$ starting from $e$ at most $k$ times.

HotStar and HotSee employ different approaches to perform the make-route task proposed in this research. Each approach is presented in Algorithms 2 and 3 respectively and are explained in the next subsections.

\subsection{HotStar Heuristic}

The HotStar approach (standing for Hot Segments Linkage $\mathrm{A}^{*}$ based Heuristic) is based on $A^{*}$. The $A^{*}$ algorithm is a widely used graph traversal and path search algorithm that avoids expanding paths that are already expensive [Hart] 
et al., 1968]. From a source vertex in $G$, the $A^{*}$ algorithm aims to find a shortest (or longest) path to the given target vertex. The $A^{*}$ algorithm maintains a tree of paths starting at the source vertex and expands these paths one edge at a time until it finds the target node. At each iteration, $A^{*}$ has to decide which of its paths to expand. It does so based on the cost of the path and the cost estimation required to extend the path all the way to the target. $A^{*}$ uses a function $f(n)=g(n)+h(n)$ as the objective function, where $g(n)$ is the current cost to achieve $n$ from the source vertex, $h(n)$ is the estimated cost from $n$ to the target vertex and $f(n)$ is the estimated total cost of path through $n$ to the target. $A^{*}$ terminates when the path it chooses to extend is a path from the source vertex to the target vertex.

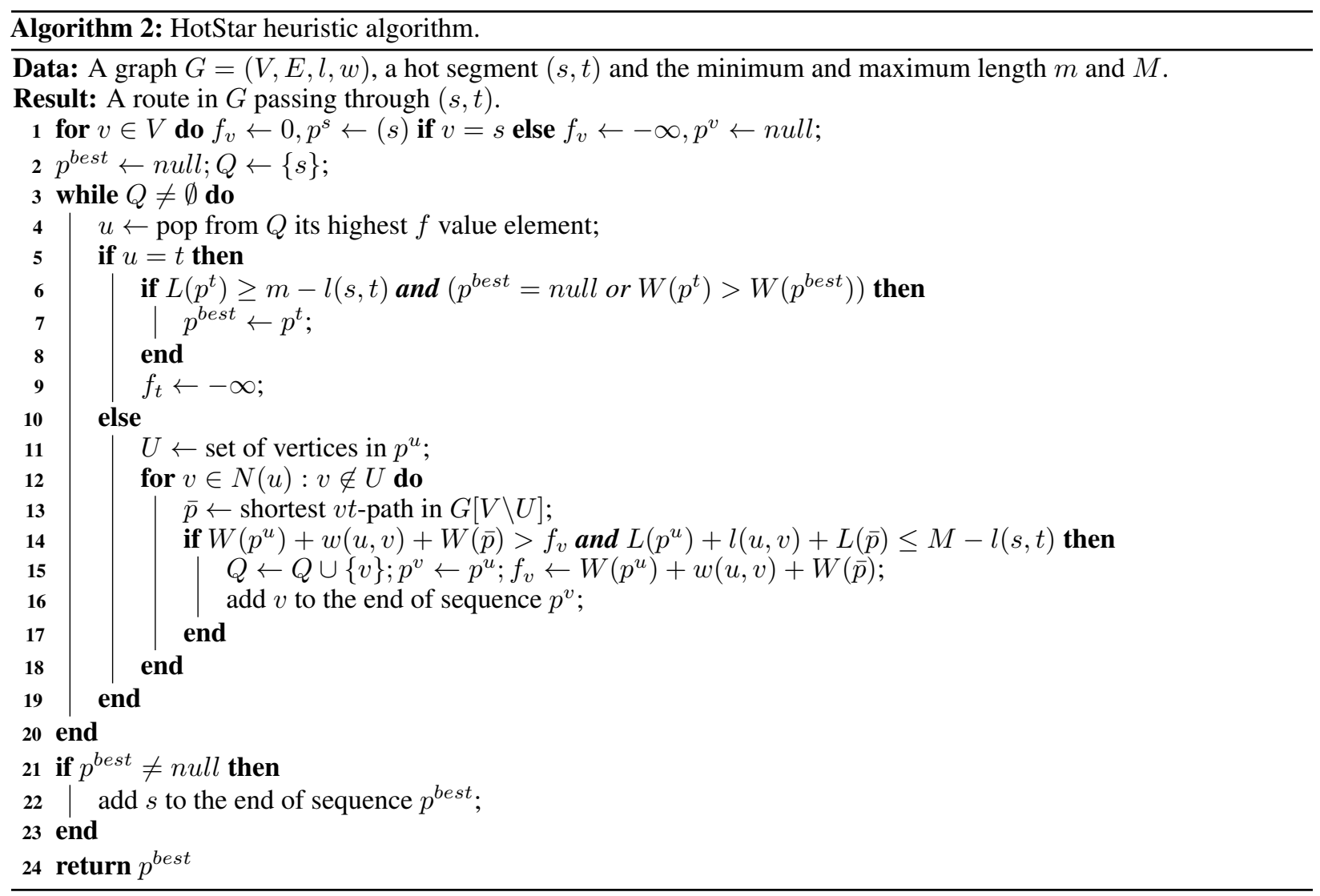

Algorithm 2 returns a route passing over a given hot segment $(s, t)$. To construct this route, Algorithm 2 searches for a path from $s$ to $t$ that maximizes the number of crimes on its edges, without passing through the edge $(s, t)$ and without violating the minimum and maximum length $m-l(s, t)$ and $M-l(s, t)$, respectively. When a path is found, Algorithm 2 adds the edge $(s, t)$ to this path, making it a cycle of $G$ and, therefore, a route. The strategy used to search for such a path is based on the $A^{*}$ procedure. Algorithm 2 treats functions $g$ and $h$ implicitly, which are related to the number of crimes. For all node $u \in V$, variable $f_{u}$ is the number of crimes covered by the current path from $s$ to $u$ (i.e., $p^{u}$ ) plus the number of crimes covered by a path with the shortest length from $u$ to $t$ in the graph $G[V \backslash U]$, where $U$ is the set of vertices in the path $p^{u}$ and $G[V \backslash U]$ is the subgraph of $G$ induced by $V \backslash U$, that is, the subgraph obtained from $G$ by deleting the vertices in $U$ together with their incident edges. This last operation corresponds to $f(u)=g(u)+h(u)$ of $A^{*}$. Algorithm 2 keeps in $Q$ the nodes to be expanded. Given a node $u$, taken from $Q$ in Line 4 and a node $v \in N(u)$ (Line 12, where $N(u)$ is the set of neighbors of $u$, Algorithm 2 expands path $p^{u}$ to $v$ if such operation increases the estimation of $v\left(f_{v}\right)$ and that yields a path, from $s$ to $t$, with length at most $M-l(s, t)$ (Line 14. Finally, different of $A^{*}$, Algorithm 2 selects the best valid found path from $s$ to $t$, saved in variable $p^{\text {best }}$, only stopping when set $Q$ is empty. $p^{\text {best }}$ is updated whenever $t$ is the node taken from $Q$ in Line 4 and $p^{t}$ has length at least $m-l(s, t)$ and covers more crimes than the current $p^{\text {best }}$. In this case, $p^{\text {best }}$ receives $p^{t}$ (Line 7 and $f_{t}$ receives $-\infty$ (Line 9 ) to let $p^{t}$ be available to receive another path. Although this approach aims to find a solution for creating hot spot policing patrol routes, there is no guarantee that a route returned from Algorithm2 is the best one.

Regarding the time complexity of HotStar (Algorithm 2), the algorithm performs a depth search at most $|V|$ times (the maximum number of nodes in a path) and for each iteration $p^{u}$ can be expanded to at most $\Delta(G)$ nodes, where $\Delta(G)$ is the maximum number of neighbors of a node in $G$. Therefore, Algorithm 2 runs the path expand operation at most $O\left(\Delta(G)^{|V|}\right)$ times. As Algorithm 2 always expands using the shortest-path algorithm, it costs $O(|E|+|V| \log |V|)$ 
using Dijkstra's algorithm [Fredman and Tarjan, 1987]. In total, HotStar takes $O\left(\Delta(G)^{|V|}(|E|+|V| \log |V|)\right)$ to find a patrol route from a hot segment.

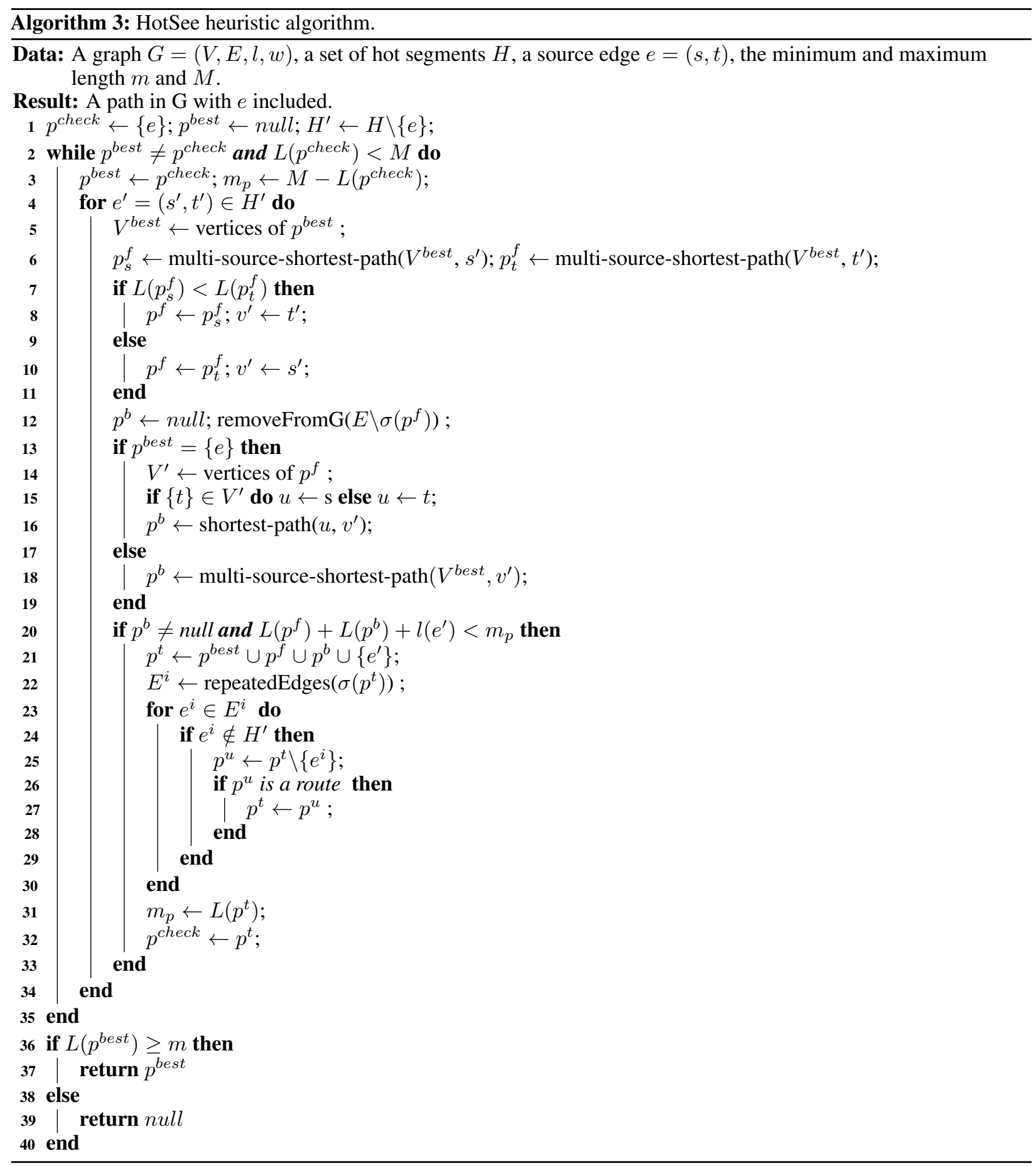

\subsection{HotSee Heuristic}

HotStar generates patrol routes that tend to be circular by avoiding traversing an edge more than once. The HotSee heuristic (standing for Hot Segments Linkage Route Generation Heuristic) bypasses the limitation of generating circular routes by creating patrol routes that may contain cycles within the route or are a cycle themselves. This means the generated patrol routes are more generic than the ones produced by HotStar. 
As performed by HotStar (Algorithm 2), HotSee (Algorithm 3) returns the best route ( $p^{\text {best }}$ ) that is found by passing through the source hot segment $e=(s, t)$. Then, Algorithm 3 tries to include in $p^{\text {best }}$ other hot segments that belong to $H$ (Line 4). To avoid $p^{\text {best }}$ from being longer than the maximum allowed length $M$ of a route, the variable $p^{\text {check }}$ temporally stores the best route and updates the $p^{\text {best }}$ (Line 3 ) when the $p^{\text {check }}$ is less than $M$ (Line 2). At the first iteration, $p^{\text {best }}$ receives from $p^{\text {check }}$ a path with only the hot segment $e$. To include any other hot segment $e^{\prime}=\left(s^{\prime}, t^{\prime}\right) \in H \backslash\{e\}$ in $p^{\text {best }}$, Algorithm 3 searches to find the shortest path in $G$ from any vertex in $p^{\text {best }}$ (or the hot segment $e$ ) to $s^{\prime}$ (called $p_{s}^{\prime}$ ) and $t^{\prime}$ (called $\left(p_{t}^{\prime}\right)$ ) (Lines 5-6) and keeps one of them with minimum length in $p^{f}$ (Lines 7 11). The principle behind $p^{f}$ is the creation of a path that goes from one vertex in $p^{\text {best }}$ to one of the vertices of another hot segment $e^{\prime}$.

Lines 13 search for another path $p^{b}$ that goes from one of the vertices in $p^{\text {best }}$ (or $e$ ) to one of the vertices from $e^{\prime}-$ however, if the source nodes in $p^{f}$ and $p^{b}$ are different, the same applies to the target nodes. It is necessary to mention that Algorithm 3 removes from $\mathrm{G}$ the edges that belong to $p^{f}$ to avoid repeating these edges during the search for $p^{b}$ (Line 12). The idea behind generating two paths from $p^{\text {best }}$ to $e^{\prime}$ is to create a cycle route that joins $p^{f}, p^{b}, p^{\text {best }}$ (or $e$ ) and $e$ (we keep the cycle route in $p^{t}$ ), but only if the length of such a route does not exceed the threshold $M$ (Lines 2021. Whenever $p^{\text {best }}$ is not only the hot segment $e$, Algorithm 3 searches for a path that goes from any vertex in $p^{\text {best }}$ $\left(V^{\text {best }}\right)$ to one of the vertices of $e^{\prime}$ (Line 18). This means Algorithm 3 initially attempts to find a cycle route $p^{t}$ that contains the hot segments $e$ and $e^{\prime}$. When $p^{t}$ is generated, in the next iterations any other hot segment in $H^{\prime}$ can join $p^{t}$ by adding new cycles.

From Lines 22 31, any repeated edge $e^{i}$ in $p^{t}$ that is not a hot segment and after removing $e^{i}$ from $p^{t}$, and the new patrol route $p^{u}$ is a valid route (see Definition 3), then $e^{i}$ can be removed. In doing so, this aims to avoid including the same edge multiple times in a single route. From Lines 31 32, Algorithm 3 keeps in $m_{p}$ the patrol route length $p^{t}$ found so far, which is also the best route (or $p^{\text {check }}$, see Line 32 in terms of complying with more hot segments in the patrol route, respecting the threshold $M$ and attempting to avoid including the same edges multiple times in a single route. Algorithm 3 at lines 36,39 verifies if the best route $\left(p^{b e s t}\right)$ respects the maximum length restriction $(M)$ and the minimum length threshold $(m)$.

At the beginning of each iteration of Algorithm 3 the variable $p^{\text {best }}$ receives the best route found so far stored in $p^{\text {check }}$ (Line 3). When it is not possible to change the best route $\left(p^{\text {best }}\right)$ by adding new hot segments, then $p^{\text {check }}$ does not change and the Algorithm 3 returns $p^{\text {best }}$ as the patrol route (Line 37 ).

The time complexity of HotSee (Algorithm 3 can be computed as follows. HotSee tries to include each hot segment in $H$ (Line 4) on the route. However, the number of times a route grows is limited to $|H|$ (Line 2). By adding a hot segment in the route, Algorithm 3 searches for the shortest-path (Lines 6 16, and 18), which takes $O(|E|+|V| \log |V|$ ) time using Dijkstra's algorithm [Fredman and Tarjan 1987]. HotSee removes from the route the repeated edges that are not hot segments (Line 22), and is equivalent to finding the Chinese postman tour and takes $O\left(|V|^{3}\right)$ [Schrijver. 2003]. This operation encompasses the shortest-path algorithm in terms of time complexity. In total, Algorithm 3 finds a route in $\left.O\left(|H|^{2}|V|^{3}\right)\right)$ time.

\section{Experimental Evaluation}

This section presents details about the experimental evaluation conducted to assess the performance of the two heuristics proposed to offer solutions for the creation of hot spot policing patrol routes. We start by describing the experimental setup and then the experimental results.

\subsection{Experimental Setup}

All experiments were conducted on an AMD Ryzen 3900x machine with 12 cores/24 threads, 64 GB of main memory running Ubuntu 20.04 LTS.

Datasets. For the experimental evaluation, and comparisons between different settings, we used two datasets provided to us from the police agency for the cities of Florianópolis and Joinville in Brazil, and three public datasets from different districts in Chicagd1. Chicago 1ST, Chicago 12TH, and Chicago 18TH districts. Each dataset contains real-world crime data and includes details about where and when the crime happened. For each dataset, we use data from February 1 , 2019 to January 31, 2020. Data from Florianópolis and Joinville were used in the research because of the interest from the police agency in using the results for a new hot spot policing program in each city. We used data from Chicago to provide an additional comparison in the use of the two heuristics and because of the data's public availability, therefore allowing for replication of our solution and comparison against other solutions that other researchers may propose. We chose the Chicago 1ST district because it is the downtown district of Chicago, and the other two districts because they were the districts with the highest number of crimes in Chicago. For each city, robberies against pedestrians were the

\footnotetext{
${ }^{1}$ https://data.cityofchicago.org/Public-Safety/Crimes-2001-to-Present/ijzp-q8t2
} 
data that were used. The number of these crimes registered in Joinville was 1327, in Florianópolis was 1184, in Chicago 1ST was 1073, in Chicago 12TH was 2013 and in Chicago 18TH was 1659. We highlight that the Chicago's crime data used in these experiments were the ones with primary type theft and robbery in the sidewalk, street, alley, and residential yard locations.

Data Preparation. The data preparation consisted of three phases: data cleaning, map matching, and data aggregation. The data cleaning process involved removing any records for areas outside of Florianopolis, Joinville, and the chosen districts of Chicago. The first part of the map matching process involved extracting street segments from Open Street Map for each study area. These street segments were then used to join each crime event to the closest street segment. In the third phase, the data aggregation process involved ordering the street segment by the total number of crime events map matched to each street segment. The top- $k$ street segments that accounted for $\alpha \%$ of crime (i.e., the most criminogenic street segments) become the hot segments and belong to $H$.

Run-time parameters. For the evaluation of both heuristics, we use the following parameters: (1) the distance threshold, which is the maximum distance between the crime location to the nearest edge in the street network graph. We only consider the crime events that are less than one hundred meters away to the nearest edge; (2) the hot segments are the top- $k$ edges with the highest number of crimes, together they should concentrate more than $\alpha \%$ of crime events. The parameter $\alpha$ is set to $50 \%$ (following the procedure used by [Weisburd 2015] to define street segments where hot spots are located); (3) The minimum $m$ and the maximum $M$ patrol route length thresholds correspond to seven hundred and one thousand and three hundred meters, respectively, based on the average distance that can be walked by a police patrol in 15 minutes [Chainey, in press 2021].

Evaluation Metrics. We evaluate the two proposed heuristics using four main metrics, all of which were previously defined in Section 2.2 Let $S$ be the set of patrol routes found by one of the heuristics. One metric (called $W$ ) is the number of crimes located on edges in $S$. Another metric relates to the proportion of the length of all the patrol routes in $S$ that are hot segments (the metric $H L F$ ), and another relates to the proportion of $S$ that is not part of any cycle in $S$ (referred to as $N R E F$ ). The fourth metric is a crime density index $(C D I)$ that measures how many times the street segments in a patrol route have more associated crimes than all the street segments from $G$. We also calculate the average and standard deviation of patrol route length in $S$ to examine the effect of parameters $m$ and $M$ on the patrol routes and to compare between the two heuristics. We apply HotStar and HotSee to the creation of 10 patrol routes, 20 patrol routes, and 30 patrol routes to examine for differences in results based on the number of hot spots policing patrol routes that are generated. This approach fits with options that a police commander would consider in practice when creating patrol routes and considering the number of police personnel to deploy to crime hot spots [Chainey, in press 2021]. We also perform a visual inspection of the patrol routes for further comparison between the two heuristics.

\subsection{Experimental Results}

\subsubsection{Quality Analysis of the results}

Table 2 lists the street network information for Florianópolis, Joinville, and the three districts from Chicago. We observe that the Brazilian cities were larger than the Chicago districts and had street segments that were almost twice the length of those in Chicago. Even though these differences existed, levels of geographic crime concentration were similar. This is illustrated in Figure 1, showing levels of crime concentration across street segments for each study area. In each study area, the proportion of street segments that accounted for $50 \%$ of crimes was between $1 \%$ and $2 \%$. In each city, approximately $0.5 \%$ of street segments accounted for $25 \%$ of crime. These findings are consistent with findings on the geographic crime concentration of robberies [Chainey et al. 2015] and indicates the high levels of crime concentration that are apparent in each of the cities included in the current study. These high levels of geographic crime concentration suggest that the implementation of a hot spot policing program in each city would be worthwhile. The higher number of hot segments in Florianópolis and Joinville in comparison to the three Chicago districts is related to the larger size of the two Brazilian study areas. To illustrate the spatial patterning of crime concentration, Figure 2 shows the distribution of the hot segments (i.e., the street segments that account for $50 \%$ of crimes) for the three districts of Chicago. The hot segments were then used as inputs for the HotStar and HotSee algorithms for creating hot spot policing patrol routes.

Tables 3 5 show the results for the metrics that were calculated from the hot spot policing patrol routes that were created using the HotStar and HotSee algorithms for each study area. We first examine the number of crimes $(W)$ on each set of routes for the two algorithms. HotStar consistently outperformed HotSee in each case. This is to be expected because HotStar works by expanding paths in the street network based on the path's cost in terms of the number of crimes. We note that in each case, the value of $(W)$ was higher for each of the Chicago districts than it was for Florianópolis and Joinville datasets. This is likely to be associated with the size of each study area and the number of crimes that are contained in a smaller number of street segments in the Chicago study areas.

With regards to the $C D I$ metric, the results indicate that in all cases, the patrol routes created by both algorithms satisfy the main property of being located in a hot spot - in each case, the results show that the density of crime along the 


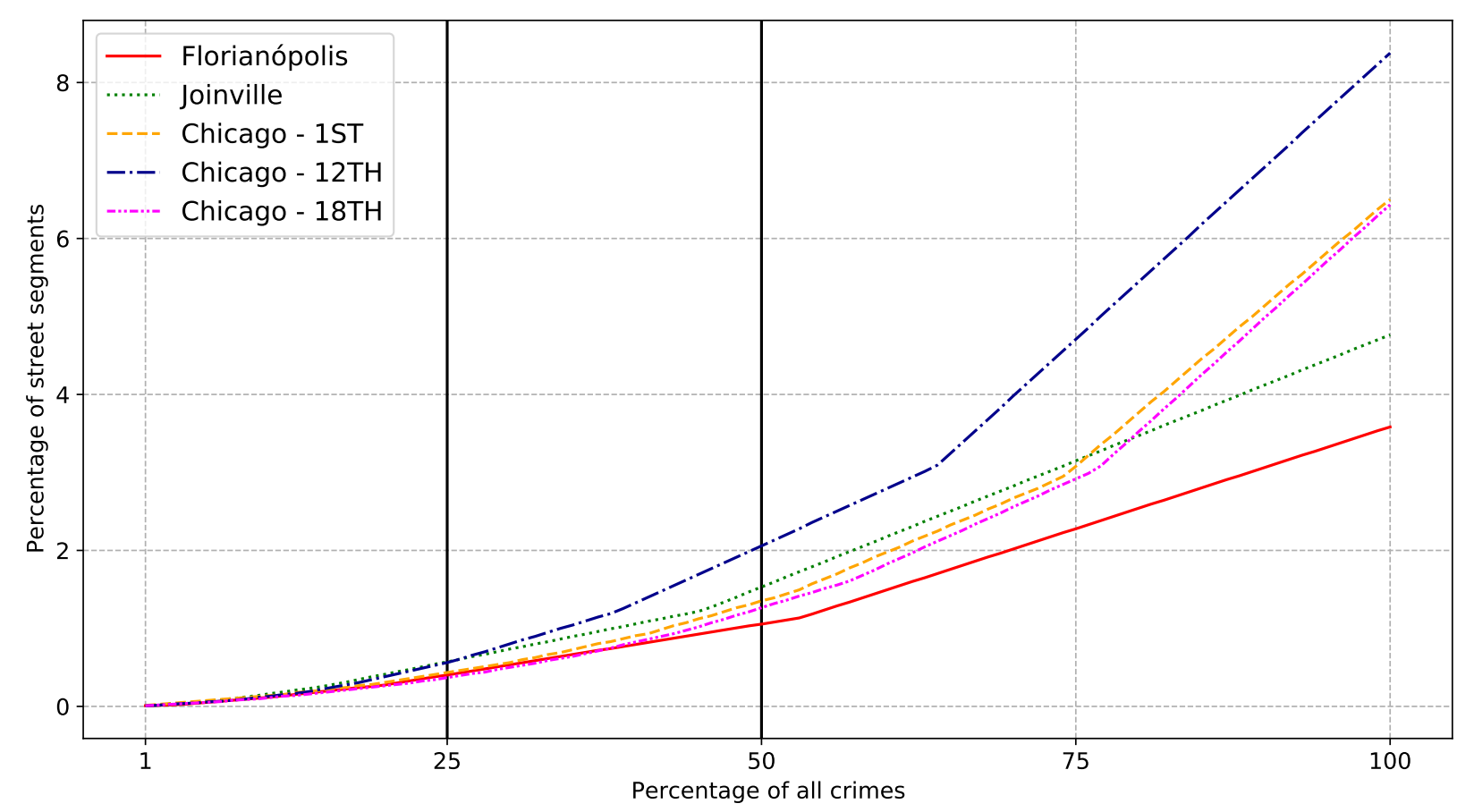

Figure 1: Crime concentration amongst street segments.

\begin{tabular}{lcccccc}
\hline \multicolumn{1}{c}{ Dataset } & $\begin{array}{c}\text { No. of } \\
\text { Vertices }\end{array}$ & $\begin{array}{c}\text { No. of } \\
\text { Edges }\end{array}$ & $\begin{array}{c}\text { Mean length } \\
\text { of edges (m) }\end{array}$ & $\begin{array}{c}\text { No. of } \\
\text { Crimes }\end{array}$ & $\begin{array}{c}\text { Street segments } \\
\text { with crimes }\end{array}$ & $\begin{array}{c}\text { Hot segments } \\
\text { for 50\% of crimes }\end{array}$ \\
\hline Florianópolis & 17589 & 22663 & 102 & 1194 & 812 & 242 \\
Joinville & 15311 & 20508 & 128 & 1333 & 977 & 317 \\
Chicago - 1ST & 6091 & 7830 & 47 & 1073 & 509 & 106 \\
Chicago - 12TH & 9020 & 13702 & 55 & 2014 & 1148 & 282 \\
Chicago - 18TH & 7450 & 11380 & 42 & 1659 & 732 & 144 \\
\hline \hline
\end{tabular}

Table 2: Street network information and map matching of crime data for Floriánopolis, Joinville and Chicago districts.

\begin{tabular}{|c|c|c|c|c|c|c|c|}
\hline Dataset & Algorithm & CDI & $\mathrm{W}(\%)$ & NHC (\%) & ARL (std) & HLF (\%) & NREF (\%) \\
\hline Florianópolis & HotSee & 27.21 & $141(11.91 \%)$ & $43(17.99 \%)$ & $1024(122.93)$ & $3559(34.76 \%)$ & $10021(99.24 \%)$ \\
\hline Florianópolis & HotStar & 26.32 & $151(12.75 \%)$ & $38(15.70 \%)$ & $1118(75.65)$ & $3239(28.97 \%)$ & $11181(100.00 \%)$ \\
\hline Joinville & HotSee & 26.00 & $126(9.50 \%)$ & $47(14.97 \%)$ & 978 (151.37) & $5856(59.83$ & $9583(99.71 \%)$ \\
\hline Joinville & HotStar & 26.77 & $10.32 \%)$ & $46(14.51 \%)$ & 1014 & $5774\left(56.90^{\circ}\right.$ & $10148(100.00 \%)$ \\
\hline Chicago - 1ST & HotSee & 10.68 & $30.48 \%)$ & $49(46$. & 1070 & $3985(37.23$ & $10323(98.25 \%)$ \\
\hline Chicago - 1ST & HotStar & 11.29 & $370(34.48 \%)$ & $50(47.17 \%)$ & $1124(51.55)$ & $4140(36.82 \%)$ & $11243(100.00 \%)$ \\
\hline Chicago - 12TH & HotSee & 14.35 & $392(19.47 \%)$ & $66(23.40 \%)$ & 1078 & $5902(54.73 \%)$ & $9992(97.49 \%)$ \\
\hline Chicago - 12TH & HotStar & 13.93 & $424(21.06 \%)$ & $74(26.24 \%)$ & 1142 & $5890(51.56 \%)$ & $11422(100.00 \%)$ \\
\hline Chicago - 18TH & HotSee & 11.86 & $451(27.19 \%)$ & $60(41.67 \%)$ & 1129 & $4210(37.27 \%)$ & $10824(98.10 \%)$ \\
\hline Chicago - 18TH & HotStar & 12.21 & $485(29.23 \%)$ & $63(43.75 \%)$ & $1152(33.56)$ & $4917(42.66 \%)$ & $11525(100.00 \%)$ \\
\hline
\end{tabular}

Table 3: Results for 10 patrol routes. 


\begin{tabular}{|c|c|c|c|c|c|c|c|}
\hline Dataset & Algorithm & CDI & $\mathbf{W}(\%)$ & NHC (\%) & ARL (std) & HLF (\%) & NREF (\%) \\
\hline Florianópolis & HotSee & 20.53 & $210(17.74 \%)$ & $66(27.62 \%)$ & $1010(119.88)$ & $6861(33.94 \%)$ & $19728(98.97 \%)$ \\
\hline Florianópolis & HotStar & 20.55 & $229(19.34 \%)$ & $63(26.03 \%)$ & 1086 (105.59) & $6894(31.74 \%)$ & $21720(100.00 \%)$ \\
\hline Joinv & HotSee & 21.68 & $213(16.05 \%)$ & $85(27.07 \%)$ & 44.42) & 11003( & $19266(98.87 \%)$ \\
\hline Joinville & HotStar & 21.17 & $224(1$ & $81(2$ & 1049 & 10913 & $20982(100.00 \%)$ \\
\hline Chicag & HotSee & 8.19 & 485 & 78( & 1036 & $7216(34.81 \%)$ & $19915(98.03 \%)$ \\
\hline Chicago - 1ST & HotStar & 8.48 & $560(5$ & $.58 \%)$ & 1133 & $7060(31.15 \%)$ & $00.00 \%)$ \\
\hline Chicago - 12TH & HotSee & 10.41 & $568(28.22 \%)$ & $111(39.36 \%)$ & 1061 & $9789(46.12 \%)$ & $20012(97.72 \%)$ \\
\hline Chicago - 12TH & HotStar & 10.28 & $607(30.15 \%)$ & $111(39.36 \%)$ & 1107 (86.27) & $9600(43.35 \%)$ & $22145(100.00 \%)$ \\
\hline go - 18TH & HotSee & 9.04 & $666(40.14 \%)$ & $96(66.67 \%)$ & 1085 (112.79) & $8028(36.96 \%)$ & $21175(99.02 \%)$ \\
\hline Chicago - 18TH & HotStar & 9.15 & $730(44.00 \%)$ & $93(64.58 \%)$ & 1157 (39.45) & $8157(35.23 \%)$ & $23155(100.00 \%)$ \\
\hline
\end{tabular}

Table 4: Results for 20 patrol routes.

\begin{tabular}{|c|c|c|c|c|c|c|c|}
\hline Dataset & Algorithm & CDI & $\mathrm{W}(\%)$ & NHC (\%) & ARL (std) & HLF (\%) & NREF (\%) \\
\hline Florianópolis & HotSee & 17.65 & $265(22.38 \%)$ & $89(37.24 \%)$ & $989(136.55)$ & $9417(31.72 \%)$ & $28921(98.83 \%)$ \\
\hline Florianóp & HotStar & 17.73 & $293(24.75 \%)$ & $81(33.47 \%)$ & 1073 (128.98) & $8644(26.839$ & $(100.00 \%)$ \\
\hline Joinville & HotSee & 18.81 & $275(20.72 \%)$ & $114(36.31 \%)$ & $989(1$ & $14904(50.22 \%)$ & $28600(98.63 \%$ \\
\hline Joinville & HotStar & 18.20 & $290(21.85 \%)$ & $103(32.49 \%)$ & $1053(1$ & $14028(44.40 \%)$ & $31594(100.00 \%)$ \\
\hline Chicago - 1ST & HotSee & 7.66 & $520(48.46 \%)$ & $85(80.19 \%)$ & $1007(142.84)$ & $8674(35.87 \%)$ & $22433(96.27 \%)$ \\
\hline Chicago - 1ST & HotStar & 7.09 & $684(63.75 \%)$ & $93(87.74 \%)$ & $1103(97.86)$ & $9072(27.40 \%)$ & $33110(100.00 \%)$ \\
\hline Chicago - 12TH & HotSee & 8.84 & $699(34.72 \%)$ & $152(53.90 \%)$ & $1036(116.92)$ & $14004(45.03 \%)$ & $28689(96.70 \%)$ \\
\hline Chicago - 12TH & HotStar & 8.42 & $753(37.41 \%)$ & $144(51.06 \%)$ & $1119(76.07)$ & $13007(38.74 \%)$ & $33573(100.00 \%)$ \\
\hline Chicago - 18TH & HotSee & 7.54 & $793(47.80 \%)$ & $120(83.33 \%)$ & 1061 (130.12) & $11956(37.53 \%)$ & $29424(96.40 \%)$ \\
\hline Chicago - 18TH & HotStar & 7.51 & $891(53.71 \%)$ & $109(75.69 \%)$ & $1148(46.03)$ & $9955(28.90 \%)$ & $34445(100.00 \%)$ \\
\hline
\end{tabular}

Table 5: Results for 30 patrol routes.

patrol routes is greater than the crime density for the street network as a whole. For example, for the municipality of Florianópolis, and for the calculation of 20 patrol routes, both algorithms created routes with a CDI of 20.5 , which means that the probability of the police patrol being located on a street segment that has previously experienced a crime is 20.5 times greater than the average probability for a street segment in the entire study area. In comparing both algorithms, Tables 3 . 5 show that for each study area and the number of patrol routes, the CDIs values were very similar, indicating no substantial difference between the algorithms for this metric.

From Tables 3, 5 we also observe that the patrol routes created by HotSee generated values for the HLF metric that were higher than those for HotStar in the majority of cases. This means that patrol routes created by HotSee tend to have more hot segments within each route than for the patrol routes created using HotStar. This was to be expected because a procedure associated with HotSee is how it attempts to maximize the inclusion of hot segments as the patrol route is extended from its starting position. By examining the number of hot segments covered (the NHC metric), we also note that the patrol routes created by HotSee contain more hot segments in the majority of cases in comparison to the routes created using HotStar. Overall, we observe that HotSee produces patrol routes that contain a higher number of hot segments along the patrol route path.

From Tables 3/5 we observe that HotStar consistently outperforms HotSee for NREF metric - the metric that refers to the number of non repeated edges within patrol routes. This was to be expected because a procedure associated with the HotStar approach is for it to generate paths within a patrol route that minimizes the requirement for a patrol to double-back along the same street segment. We visually illustrate this procedural difference between HotStar and HotSee in the next section. Tables 3 , 5 also show the average length of each patrol route (ARL) was approximately $1000 \mathrm{~m}$ in each case, illustrating how each approach worked at containing the length of the patrol routes between the minimum and maximum settings that were previously defined.

The HotSee approach only computes the shortest paths between hot segments and does not consider the total number of criminal events across a potential route. In this way, a higher number of hot segments in the study region could offer more routes to be found. On the other hand, regions with a low concentration of hot segments restrict the number of patrol routes to be discovered. If there is only one hot segment in the analyzed region, the HotSee algorithm creates a minimum cyclic route, including only this hot segment. In this manner, other possible routes that may include more crimes are not tested or even allowed to exceed the minimum length parameter, making it a candidate route in greedy heuristics (Algorithm 1). It is possible to observe this limitation in the experiment of 30 routes for the Chicago 1ST dataset, in which the algorithm was able to generate only 24 routes. In this experiment, the proportion of street segments responsible for $50 \%$ of the crimes was considered, and the increase in the parameter $(\alpha)$ increased the number of hot segments in the study area, increased the number of routes tested, and increased the runtime of the algorithm. 


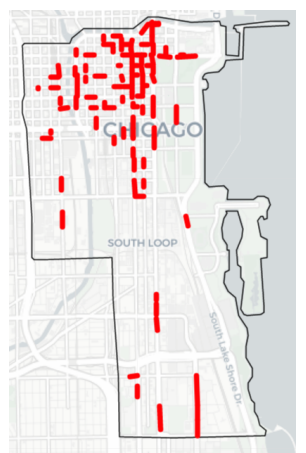

(a) Chicago 1ST district.

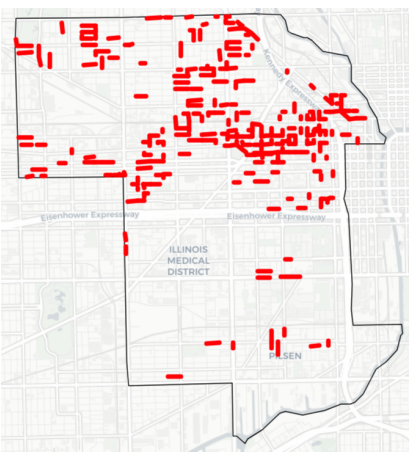

(b) Chicago $12 \mathrm{TH}$ district.

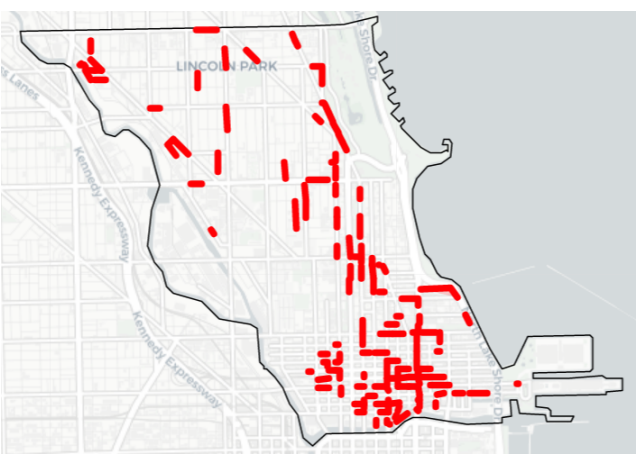

(c) Chicago $18 \mathrm{TH}$ district.

Figure 2: Comparison of Hot Segments between different Chicago districts.

In terms of run time performance, the longest time taken to execute the algorithms HotStar and HotSee was 413s and 249 s respectively, and in both cases for the creation of 30 routes for Chicago's 18th District. The longer time associated with HotStar was because of how the algorithm searches for suitable edges to include in a patrol route, with this being different to HotSee that mainly seeks to identify a hot segment that is close by. The main finding, however, was the patrol routes were created within a few minutes, with this likely to be significantly quicker than the manual creation of patrol routes by a police commander.

\subsection{Visual Inspection}

Visual inspection of outputs is a useful tool whenever (1) different approaches produce patrol routes that have different semantics, (2) different parameter settings create patrol routes that perform well in terms of the metrics by which they are measured but where these metrics reflect the differences in procedures that different approaches follow, or (3) when ground truth is not available. Visual inspection of outputs is also a common approach used in other studies, for example [da Silva et al. 2020, Li et al. 2007]. In this section, we examine the patrol routes generated by both algorithms by means of visual inspection. We use the patrol routes created for the Chicago 12TH district to illustrate these differences and because the crime data for this study area is publicly available, and hence to allow for other researchers to replicate and compare using other approaches.

Figures 3a, 3c and 3e show patrol routes created using HotStar and Figures 3b, 3d and 3f show the patrol routes created using HotSee. Blue and red lines refer to patrol routes and hot segments, respectively. The numbers in Figure 3 refer to the number of crimes on the street segments that make up the patrol routes. We observe in each case that the patrol routes created using the two approaches are slightly different. Both approaches have identified the same area where a hot spot policing patrol should be located, and consist of many of the same street segments, however the route created by HotStar, see (Figure 3a) for example, extends out further in its attempt to include street segments in the set of all segments within a patrol route that has the highest number of crimes. This is different to HotSee, that greedily seeks to include more hot segments on the route, and then closing this route before the maximum length of the patrol route is surpassed (Figure 3b). This results in the HotSee algorithm generating, in this example, a shorter patrol route in this area, and with the HotStar approach creating a route on which more crimes had occurred.

Figures $3 \mathrm{c}$ and $3 \mathrm{~d}$ also illustrate these differences in how the different approaches seek street segments with crimes in comparison to prioritizing street segments that are hot segments. These second examples also show how the HotStar approach worked to minimize the number of edges that are included more than once in the creation of a patrol route. In 3c. the patrol route is circular with each street segment only traversed once in comparison to $3 \mathrm{~d}$ where several street segments are traversed more than once. However, in this example, the patrol route generated by HotSee is a route in which more crimes had occurred because of its inclusion of more hot segments than the route shown in $3 \mathrm{c}$ - the patrol route generated using HotSee included the hot segments A and B shown in this example. Finally, Figure 3f also illustrates how the HotSee algorithm seeks to maximize the number of hot segments in the patrol routes it creates. In comparison to the patrol route created using HotStar (Figure 3e), the route created using the HotSee algorithm included the hot segment A. The HotStar algorithm created a circular patrol path containing two hot segments, and it is likely did not include hot segment A because this would have increased the route's length beyond the maximum threshold.

\section{Discussion, limitations and conclusion}

Hot spot policing involves the deployment of police patrols to the specific locations where crime is known to have previously concentrated. A key factor to the success of a hot spot policing intervention is to ensure that the police 


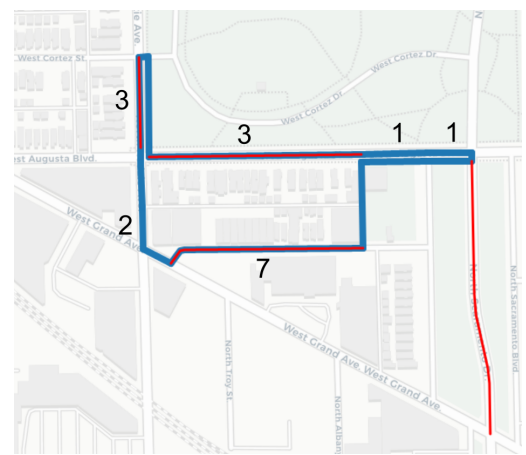

(a) No. of Crimes: 17; Length of Route: $1116.6 \mathrm{~m}$

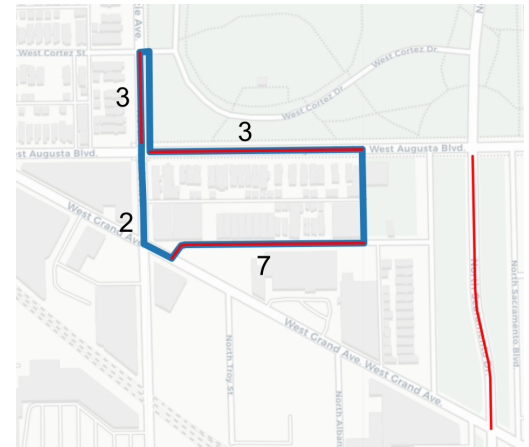

(b) No. of Crimes: 15, Length of Route: $882.1 \mathrm{~m}$.

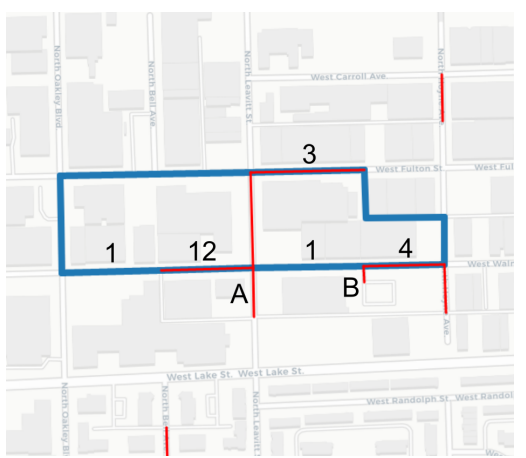

(c) No. of Crimes: 21; Length of Route: $1010.2 \mathrm{~m}$.

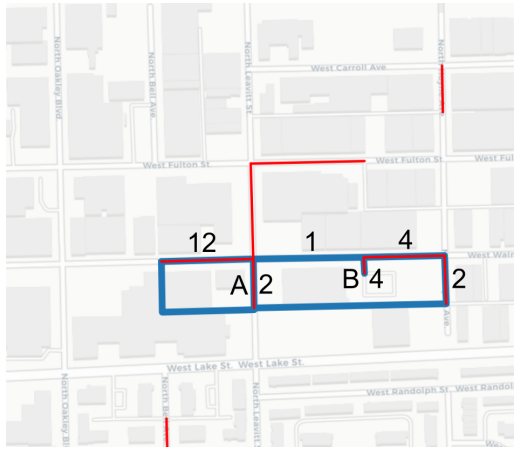

(d) No. of Crimes: 25; Length of Route: $841.6 \mathrm{~m}$.

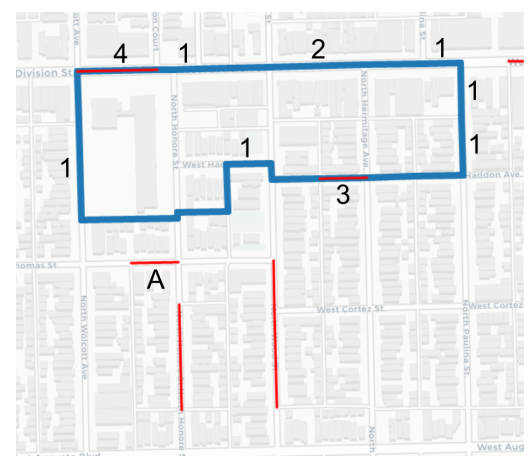

(e) No. of Crimes: 15; Length of Route: $1155.7 \mathrm{~m}$

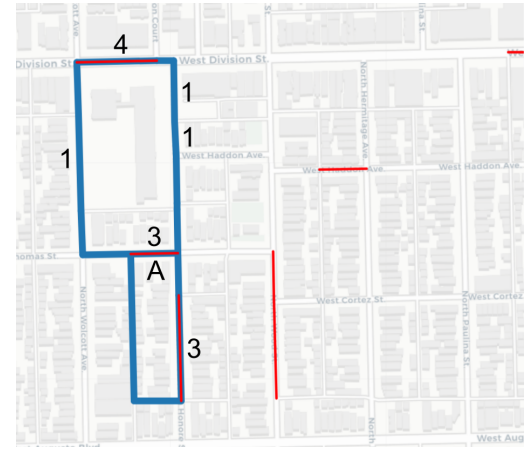

(f) No. of Crimes: 13; Length of Route: $1016.7 \mathrm{~m}$.

Figure 3: Patrol Routes (blue lines) generated by HotStar (a, c, e) and HotSee (b, d, f) algorithms in different areas of Chicago $12 \mathrm{TH}$ district. Red lines represent hot segments.

patrols are accurately and precisely deployed to the locations where these patrols will have greatest impact. This requires hot spot patrol routes to be created with care and to ensure they include the specific street segments where crime has previously concentrated. Often, these hot segments are not located next to each other, meaning that patrol routes need to be designed that include other street segments that are traversed to reach street segments on which higher levels of crime have been experienced. To date, the creation of hot spot policing patrol routes has mainly been a manual task for police commanders to perform, requires good analytical skills to identify where the crime hot spots are located and skill in drawing patrol routes in these areas. In this study we have introduced two heuristics (HotStar and $\mathrm{HotSee}$ ) for creating patrol routes. Each approach created patrol routes in locations where crime had previously highly concentrated, with each route being practical in its design (such as the length of the patrol route to conform with foot patrol requirements). There was little difference between the two approaches in the density of crime on the set of patrol routes that each approach created, however the HotStar patrol routes maximized the coverage area of patrols by minimizing the number of edges that were traversed more than once in a single patrol route. This meant that more street segments were often included in a HotStar generated patrol route than in a patrol route created using HotSee. We do, however, recommend further research that compares how a police commander would create hot spot policing patrol routes and if their preference was to use the outputs generated by HotStar rather than HotSee. We also anticipate other future research that uses the patrol route outputs the algorithms generate and comparing the impact of these patrol routes in decreasing crime in comparison to patrol routes created using other means.

The focus of the current study has been to determine where hot spot policing patrols should be located. Hot spots of crime are not hot spots all of the time, and so the creation of a hot spot policing deployment plan also needs to consider when crime concentrates in these locations. Currently, this is a manual task that requires a police commander to review the crime data for each patrol route, identify when crime concentrates along each route, and from this create a deployment plan that specifies when the policing patrols should be present. Therefore, we encourage further research on hot spot policing patrol route creation that considers when crime concentrates so that patrol routes are sensitive to both spatial and temporal characteristics of crime concentration. 
Each of the two heuristics (HotStar and HotSee) have some limitatios which we describe and which we identify could improve how each heuristic operates. Since the HotSee heuristic implements a greedy strategy, it is sensitive to the concentration of hot segments in the region of interest for which the algorithm computes the patrol routes. Thus, in regions with few hot segments, this heuristic limits its search for solutions and can generate fewer routes than are intended. For example, in the Chicago 1ST dataset experiment, the HotSee heuristic generated only 24 routes, while the HotStar heuristic generated the intended 30 routes. Thus, a possible improvement for the HotSee algorithm is to include the number of crimes on each edge when computing patrol routes. We also aim to identify other efficient strategies for creating hot spot policing patrol routes, and adapt the HotStar approach to bypass its exponential complexity. One approach could be to not use the $A^{*}$ search procedure and instead use the Bellmon Ford algorithm that runs in polynomial time. We also recommend other researchers design other algorithms for creating hot spot policing patrol routes and using the same metrics we have used in the current study to compare their results against ours.

The patrol routes created in this study were designed for foot patrol purposes. This was in response to the type of crime for which the hot spot policing intervention was required - robberies against pedestrians in street settings. The HotStar and HotSee algorithms are flexible for creating vehicle hot spot policing patrols as each approach can use other types of crime data (e.g., thefts of vehicles) and parameter settings for the minimum and maximum length of the patrol can be easily adjusted. We anticipate conducting further research that creates hot spot policing vehicle patrol routes using our algorithms. This research would include using directed graphs of the street network so that patrol routes were constrained to the direction of travel that was possible along a street segment.

Hot spot policing is an effective type of intervention for decreasing crime. To date, the task of creating patrol routes for a hot spot policing purposes has mainly been a manual task requiring skills in crime analysis and knowledge of hot spot policing. The heuristics we introduce in this paper aim to improve the task of creating hot spot police patrol routes by automating their creation and improving the specification of the routes where hot spot policing patrols are assigned.

\section{Acknowledgements}

The work was supported by a grant of the National Secretary of Public Safety of the Minister of Justice - Project SINESP Big Data and Artificial Intelligence. This work was also partially supported by Ceará Government's Chief-Scientist Program under the Project Citizen Platform.

Declarations of interest: none.

\section{References}

Jerry H Ratcliffe and Evan T Sorg. Foot Patrol: Rethinking the Cornerstone of Policing. Springer, 2017.

Larry Gaines, Christine Famega, and Gisela Bichler. Police response to burglar alarms study: San bernardino county. Center for Criminal Justice Research. San Bernardino, California: California State University, 2007.

George L Kelling, Tony Pate, Duane Dieckman, and Charles Brown. The Kansas City Preventive Patrol Experiment: A Tecnical Report. Police Foundation Washington, DC, 1974.

Lawrence W Sherman, Patrick R Gartin, and Michael E Buerger. Hot spots of predatory crime: Routine activities and the criminology of place. Criminology, 27(1):27-56, 1989.

Anthony A Braga, Brandon Turchan, Andrew V Papachristos, and David M Hureau. Hot spots policing of small geographic areas effects on crime. Campbell Systematic Reviews, 15(3):e1046, 2019a.

Spencer P Chainey, Gastón Pezzuchi, Néstor Octavio Guerrero Rojas, José Luis Hernandez Ramirez, Joana Monteiro, and Erwin Rosas Valdez. Crime concentration at micro-places in latin america. Crime Science, 8(1):1-5, 2019.

YongJei Lee, John E Eck, O SooHyun, and Natalie N Martinez. How concentrated is crime at places? a systematic review from 1970 to 2015. Crime Science, 6(1):1-16, 2017.

David Weisburd. The law of crime concentration and the criminology of place. Criminology, 53(2):133-157, 2015.

Spencer Chainey. Understanding crime: Analyzing the Geography of Crime. Esri Press, in press 2021.

Christine N Famega, James Frank, and Lorraine Mazerolle. Managing police patrol time: The role of supervisor directives. Justice Quarterly, 22(4):540-559, 2005.

Anthony Allan Braga and David Weisburd. Policing Problem Places: Crime Hot Spots and Effective Prevention. Oxford University Press on Demand, 2010.

Lawrence W Sherman and David Weisburd. General deterrent effects of police patrol in crime "hot spots": A randomized, controlled trial. Justice quarterly, 12(4):625-648, 1995a. 
Lawrence W Sherman and David Weisburd. Does patrol prevent crime? the minneapolis hot spots experiment. Crime Prevention in the Urban Community, 1995b.

Spencer P Chainey, Rodrigo Serrano-Berthet, and Federico Veneri. The impact of a hot spot policing program in montevideo, uruguay: an evaluation using a quasi-experimental difference-in-difference negative binomial approach. Police Practice and Research, pages 1-16, 2020.

Jerry H Ratcliffe, Travis Taniguchi, Elizabeth R Groff, and Jennifer D Wood. The philadelphia foot patrol experiment: A randomized controlled trial of police patrol effectiveness in violent crime hotspots. Criminology, 49(3):795-831, 2011.

David Weisburd and Lorraine Green. Policing drug hot spots: The jersey city drug market analysis experiment. Justice Quarterly, 12(4):711-735, 1995.

Martin A Andresen and Kevin CY Lau. An evaluation of police foot patrol in lower lonsdale, british columbia. Police Practice and Research, 15(6):476-489, 2014.

Brian A Lawton, Ralph B Taylor, and Anthony J Luongo. Police officers on drug corners in philadelphia, drug crime, and violent crime: Intended, diffusion, and displacement impacts. Justice Quarterly, 22(4):427-451, 2005.

A. A. Braga, B. S. Turchan, and A. V. Papachristos. Hot spot policing and crime reduction: an update of an ongoing systematic review and meta-analysis. Journal of Experimental Criminology, 15:289-311, $2019 \mathrm{~b}$.

Daniela Collazos, Eduardo García, Daniel Mejía, Daniel Ortega, and Santiago Tobón. Hot spots policing in a high-crime environment: An experimental evaluation in medellin. Journal of Experimental Criminology, pages 1-34, 2020.

S. P. Chainey, Pezzuchi G., J. L. H. Rojas, N. O. G.and Ramirez, J. Monteiro, and E. R. Valdez. Crime concentration at micro-places in latin america. Crime Sci, 8(5), 2015.

David Weisburd, Cody W Telep, and Brian A Lawton. Could innovations in policing have contributed to the new york city crime drop even in a period of declining police strength?: The case of stop, question and frisk as a hot spots policing strategy. Justice Quarterly, 31(1):129-153, 2014.

S. P Chainey and J. Monteiro. The dispersion of crime concentration during a period of crime increase. Security Journal, 32:324-341, 2019.

Andrea SN Curman, Martin A Andresen, and Paul J Brantingham. Crime and place: A longitudinal examination of street segment patterns in vancouver, bc. Journal of Quantitative Criminology, 31(1):127-147, 2015.

Daniel Ortega, Daniel Mejía, and Karen Ortiz. Un análisis de la criminalidad urbana en colombia, 2015.

Christopher S Koper. Just enough police presence: Reducing crime and disorderly behavior by optimizing patrol time in crime hot spots. Justice quarterly, 12(4):649-672, 1995.

S.P. Chainey, N.T. Alvarado, and R. Serrano-Berthet. Hot spot policing: an evidence-based practice guide for police in latin america and the caribbean, in press 2021.

Maite Dewinter, Christophe Vandeviver, Tom Vander Beken, and Frank Witlox. Analysing the police patrol routing problem: A review. ISPRS International Journal of Geo-Information, 9(3):157, 2020.

Victor Pillac, Michel Gendreau, Christelle Guéret, and Andrés L Medaglia. A review of dynamic vehicle routing problems. European Journal of Operational Research, 225(1):1-11, 2013.

Miguel Camacho-Collados and Federico Liberatore. A decision support system for predictive police patrolling. Decision Support Systems, 75:25-37, 2015.

Kenneth Chelst. An algorithm for deploying a crime directed (tactical) patrol force. Management Science, 24(12): 1314-1327, 1978.

Bernard O Koopman. The theory of search: Iii. the optimum distribution of searching effort. Operations research, 5(5): 613-626, 1957.

Pei-Fen Kuo, Dominique Lord, and Troy Duane Walden. Using geographical information systems to organize police patrol routes effectively by grouping hotspots of crash and crime data. Journal of Transport Geography, 30:138-148, 2013.

Huanfa Chen, Tao Cheng, and Sarah Wise. Developing an online cooperative police patrol routing strategy. Computers, Environment and Urban Systems, 62:19-29, 2017.

Sudarshan S Chawathe. Organizing hot-spot police patrol routes. In 2007 IEEE Intelligence and Security Informatics, pages 79-86. IEEE, 2007.

Peter E Hart, Nils J Nilsson, and Bertram Raphael. A formal basis for the heuristic determination of minimum cost paths. IEEE transactions on Systems Science and Cybernetics, 4(2):100-107, 1968. 
Michael L Fredman and Robert Endre Tarjan. Fibonacci heaps and their uses in improved network optimization algorithms. Journal of the ACM, 34(3):596-615, 1987.

Alexander Schrijver. Combinatorial Optimization: Polyhedra and Efficiency, volume 24. Springer Science \& Business Media, 2003.

Ticiana L Coelho da Silva, Francesco Lettich, José Antônio Fernandes de Macêdo, Karine Zeitouni, and Marco A Casanova. Online clustering of trajectories in road networks. In IEEE International Conference on Mobile Data Management, pages 99-108. IEEE, 2020.

Xiaolei Li, Jiawei Han, Jae-Gil Lee, and Hector Gonzalez. Traffic density-based discovery of hot routes in road networks, 2007. 